\title{
An Empirical Analysis of the Relationship between Energy Consumption Structure and Environmental Pollution in Beijing
}

\author{
Yan Shigang ${ }^{1}$, Deng Xin ${ }^{2} \&$ Li Lexuan ${ }^{1}$ \\ ${ }^{1}$ School of International Economics, China Foreign Affairs University, P. R. China \\ ${ }^{2}$ School of Finance, Hunan University of Technology and Business; Science and Technology on Information \\ Systems Engineering Laboratory, National University of Defense Technology, P. R. China \\ Correspondence: Deng Xin, School of Finance, Hunan University of Technology and Business; Science and \\ Technology on Information Systems Engineering Laboratory, National University of Defense Technology, P. R. \\ China. E-mail: sunnydoe@163.com
}

Received: January 17, 2020

doi:10.5539/ijbm.v15n6p98
Accepted: April 20, 2020

Online Published: May 15, 2020

URL: https://doi.org/10.5539/ijbm.v15n6p98

\begin{abstract}
With the economic development and the increased energy consumption, challenges of environmental pollution control have been intensified in Beijing. To promote sustainable socioeconomic development, energy consumption restructure and the environment governance have become important issues of Beijing. Based on the grey correlation model, this paper analyzed the relationship between energy consumption structure and environmental pollution in Beijing. It is empirically shown that coal and oil consumption in Beijing's energy consumption were highly correlated with environmental pollution, while natural gas consumption had the least impact on environmental pollution emissions. The findings of the study provided an empirical support to how to optimize the energy consumption structure and decrease the environment pollution.
\end{abstract}

Keywords: Beijing, empirical analysis, energy consumption, environmental pollution

\section{Introduction}

Energy demand in Beijing continues to grow on the back of relatively fast socioeconomic development. Beijing's energy production was 37.34 million tons of standard coal and energy consumption of Beijing reached 71.33 million tons of standard coal in 2017(BMBS, 2018). With the economic development and the increased energy consumption, challenges of environmental pollution control have been intensified in Beijing. In 2017, the average annual concentration of PM2.5 reached $57.1 \mu \mathrm{g} / \mathrm{m}^{3}$ in 2017 , which ranking the $26^{\text {th }}$ among 31 provinces and municipalities of China (NBS, 2018). While the external dependence of energy continues to rise, the total amount of atmospheric pollutants still exceeds the environmental capacity. Especially since the increase of haze weather in 2014, air quality and residents' health have been seriously affected, which makes it very urgent for Beijing to control environmental pollution, and strengthen ecological construction.

There have been many attempts in the energy economics literature to determine the link between energy, environmental degradation or pollution, and economic growth. Yuan et al. (2014) built resource-environment performance index to analyze the relationship between the energy consumption and environment pollution. Based the data collected from the developed provinces and less developed provinces in China from 2000 to 2013, the research showed the energy consumption structure and energy efficiency would help to decrease the environment pollution. Zhu et al. (2015) analyzed the relationship among China energy production, energy consumption and economic development with gray correlation analysis. Zeng and $\mathrm{Su}$ (2006) used gray correlation method to analyze the relationship between energy consumption and environmental quality of China. Qian (2010) and Zhang et al. (2015) put forward that the increase of population and industrial sector restructure led to the increase of energy consumption and the aggravation of environmental pollution in Beijing. Liu (2019) stated that Beijing's energy consumption would reach its peak by 2030 and the environment pollution would be a big challenge to deal with in the historical period of the new normal of economic development.

The construction of ecological civilization is an important strategy for "Green Beijing" and the construction of a world city with Chinese characteristics. To promote sustainable development of economy, energy consumption restructure and the environment governance have become important issues of Beijing. Moreover, Beijing's 
energy consumption would increases in the next ten years, which will lead to the aggravation of environmental pollution. Therefore, the research attempts to study the relationship between energy consumption structure and environment pollution of Beijing based on the grey correlation method.

\section{The Status of Energy Consumption and Environmental Pollution in Beijing}

As a large-scale city with a permanent population of more than 20 million and a large population density, Beijing faced huge challenges to resource balance and environmental carrying. With the rapid economic growth and higher energy consumption, the contradiction between population resources and environment of Beijing is more prominent (Zhou, 2016).

\subsection{Current Situation of Energy Consumption in Beijing}

With the rapid development of the social economy, the total amount of energy production and consumption in Beijing is correspondingly increasing. In 2017, Beijing's energy production reached 37.34 million tons of standard coal, recording a decrease of $4.7 \%$ compared to the energy production in 2010 . The total energy consumption was 71.33 million tons of standard coal in 2017 , which was $12.2 \%$ higher than the energy consumption in 2010 (BMBS, 2018). Table 1 shows the energy consumption of Beijing from 2010 to 2017. From the perspective of energy consumption varieties, it has three characteristics:

First, the proportion of coal consumption has gradually decreased. In 2010, the total consumption of coal in Beijing was 19.68 million tons, accounting for $29.6 \%$ of the total consumption. The coal consumption in 2017 was 4.03 million tons, accounting for $5.65 \%$ of the total energy consumption (BMBS, 2018). Compared to the coal consumption in 2010, the coal consumption decreased $79.52 \%$. However, compared with the world cities, the proportion of coal consumption is still high. There is basically no coal burning in the energy consumption of the world cities like London and Tokyo.

Second, the consumption of oil products such as gasoline and kerosene has increased since 2010. In 2010, gasoline consumption was 3.63 million tons, and kerosene consumption was 3.93 million tons (BMBS, 2011). In 2017, gasoline consumption reached 4.90 million tons, recording an increase of $35.0 \%$ compared to gasoline consumption in 2010. In 2017, Kerosene consumption was 6.44 million tons, which was $63.9 \%$ higher than the kerosene consumption $\mathrm{n}$ in 2010(BMBS, 2018).

Finally, natural gas consumption has increased by a considerable margin. Natural gas consumption was 7.48 billion cubic meters in 2010, accounting for $14.58 \%$ of the total energy consumption in Beijing (BMBS, 2011). In 2017 , natural gas consumption reached 16.46 billion cubic meters, accounting for $33.80 \%$ of the total energy consumption in Beijing.

Table 1. Beijing's energy consumption from 2010 to 2017 (10000 tons of SCE)

\begin{tabular}{lllll}
\hline Year & $\begin{array}{l}\text { Oil } \\
\text { consumption }\end{array}$ & Coal & Natural gas consumption & Electricity consumption \\
\hline 2010 & 1967.63 & 1881.77 & 927.21 & 286.18 \\
2011 & 2105.99 & 1897.44 & 896.90 & 287.88 \\
2012 & 2074.91 & 1655.47 & 1123.12 & 275.69 \\
2013 & 2164.42 & 1567.34 & 1223.75 & 235.34 \\
2014 & 2224.24 & 1391.52 & 1440.71 & 280.08 \\
2015 & 2298.35 & 937.43 & 1985.18 & 274.10 \\
2016 & 2292.49 & 682.94 & 2205.47 & 459.47 \\
2017 & 2410.90 & 403.01 & 2268.24 & 456.50 \\
\hline
\end{tabular}

Source: Beijing Statistical Yearbook 2018 (BMBS).

\subsection{Beijing's Environmental Governance Tasks}

Beijing actively strengthens the overall planning and dispatching mechanism for environmental protection, and adopts measures such as regulation revision, policy guidance, standard setting and technological innovation to gradually improve environmental quality (Qian, 2010).

In terms of atmospheric management, sulfur dioxide $\left(\mathrm{SO}_{2}\right)$ in the air of Beijing continues to decrease, and the concentrations of inhalable particulate matter (PM10) and PM2.5 are gradually decreasing. According to the Beijing Municipal Bureau of Statistics (2011), Beijing's sulfur dioxide emissions were 115,050 tons in 2010. In 
2017, sulfur dioxide emissions reached 20,085 tons, with a drop of $82.54 \%$. In 2010 , the annual average day value of inhalable particulate matter was $0.121 \mathrm{mg} / \mathrm{m}^{3}$, and in 2017 it was reduced to $0.084 \mathrm{mg} / \mathrm{m}^{3}$, with a decrease of $30.59 \%$. The PM2.5 indicator was officially included in the air monitoring index by the Ministry of Environmental Protection in 2013. The average annual concentration of PM2.5 in Beijing was $89.5 \mu \mathrm{g} / \mathrm{m}^{3}$ in 2013 . The average annual concentration of PM2.5 reached $57.1 \mu \mathrm{g} / \mathrm{m}^{3}$ in 2017 , regarding a decrease of $36.2 \%$ compared to that in 2013 (BMBS, 2018).

Although the government of Beijing made a great advance in the control of average annual concentration of PM2.5, the average annual concentration of PM2.5 was far beyond the most of main province and municipality of China. In 2017, the average annual concentration of PM2.5 in Beijing ranked the $26^{\text {th }}$ among 31 provinces and municipalities of China as shown in table 2. In terms of pollutant emission reduction, Beijing's industrial wastewater discharge has remained high. In 2010, industrial wastewater emissions were 96.53 million tons. In 2017, industrial wastewater emissions reached 84.94 million tons, with an increase of $4.93 \%$ during the eight years.

Table 2. Average PM2.5 of province and municipality in China

\begin{tabular}{|c|c|c|c|c|}
\hline Rank & $\begin{array}{l}\text { Province and } \\
\text { Municipality }\end{array}$ & $\begin{array}{l}\text { Average PM2.5 in } 2015 \\
\left(\mu \mathrm{g} / \mathrm{m}^{3}\right)\end{array}$ & $\begin{array}{l}\text { Average PM2.5 in } 2016 \\
\left(\mu \mathrm{g} / \mathrm{m}^{3}\right)\end{array}$ & $\begin{array}{l}\text { Average PM2.5 in } 2017 \\
\left(\mu \mathrm{g} / \mathrm{m}^{3}\right)\end{array}$ \\
\hline 1 & Xizang & 25.3 & 25.7 & 17.9 \\
\hline 2 & Hainan & 20.1 & 18.6 & 18.7 \\
\hline 3 & Yunan & 27.6 & 26.2 & 24.9 \\
\hline 4 & Fujian & 28.6 & 27.1 & 26.8 \\
\hline 5 & Guizhou & 35.1 & 34.0 & 31.3 \\
\hline 6 & Qinghai & 44.3 & 39.3 & 32.1 \\
\hline 7 & Guangdong & 33.8 & 31.7 & 33.4 \\
\hline 8 & Inner Mongolia & 41.6 & 36.4 & 34.8 \\
\hline 9 & Gansu & 41.5 & 39.3 & 37.1 \\
\hline 10 & Guangxi & 40.3 & 37.0 & 38.7 \\
\hline 11 & Heilongjiang & 44.2 & 35.3 & 38.9 \\
\hline 12 & Shanghai & 54.2 & 45.5 & 39.3 \\
\hline 13 & Zhejiang & 48.2 & 41.0 & 39.5 \\
\hline 14 & Ningxia & 46.6 & 45.4 & 42.9 \\
\hline 15 & Jilin & 56.3 & 42.7 & 43.2 \\
\hline 16 & Sichuan & 48.3 & 48.0 & 43.2 \\
\hline 17 & Liaoning & 56.0 & 46.2 & 43.8 \\
\hline 18 & Chongqing & 54.5 & 53.0 & 44.4 \\
\hline 19 & Jiangxi & 43.0 & 44.0 & 45.8 \\
\hline 20 & Hunan & 53.2 & 48.2 & 46.8 \\
\hline 21 & Jiangsu & 57.7 & 50.0 & 48.4 \\
\hline 22 & Shandong & 68.6 & 59.9 & 52.8 \\
\hline 23 & Hubei & 66.4 & 55.9 & 53.4 \\
\hline 24 & Xinjiang & 54.3 & 61.8 & 56.0 \\
\hline 25 & Anhui & 56.7 & 53.1 & 57.0 \\
\hline 26 & Beijing & 79.5 & 72.0 & 57.1 \\
\hline 27 & Shaanxi & 53.8 & 59.3 & 58.7 \\
\hline 28 & Shanxi & 56.2 & 60.1 & 62.5 \\
\hline 29 & Tianjin & 71.4 & 70.5 & 63.8 \\
\hline 30 & Hebei & 76.8 & 70.4 & 65.6 \\
\hline 31 & Henan & 81.3 & 73.5 & 67.6 \\
\hline
\end{tabular}

Source: NBS (2018).

The green and low-carbon levels of production in Beijing continued to increase, and the total discharge of some pollutants showed a downward trend, but the total amount of pollutants discharged in Beijing still exceeded the environmental capacity (Tan, 2017). From the entire region, industrial pollution emissions still occupy an important position, especially industrial production processes will directly and indirectly discharge PM2.5 and 
soot into the ambient atmosphere. The industrial sectors that contribute more to the direct emission sources of PM2.5 and soot are metallurgy, building materials, and chemicals. At the same time, industrial sources are also important sources of gaseous pollutants such as sulfur dioxide, nitrogen oxides, and volatile organic compounds. Beijing needs to explore the optimization of energy consumption structure and the innovation of environmental pollution prevention and control mechanisms to more effectively reduce pollutant emissions and achieve coordinated development of Beijing's economic, social construction and environmental construction.

\section{Research Methodology}

The grey relational theory is a measure to verify the correlation between the two series of trends, especially for the quantitative analysis of dynamic time series. In this research, the grey correlation analysis method is used to study the relationship between energy consumption and environmental pollution (Zeng \& Su, 2006; Zhang et al., 2011; Fu, 2014; Zhu et al., 2015; Wang et al., 2018).

The basic idea of grey relational theory is to determine whether the relationship between the two sequences is close according to the similarity of the geometry of the parent sequence and the subsequence curve. Through the degree of similarity between the two sequences, the degree of correlation between the reaction sequences is opposite to the size, and the degree of similarity is proportional to the degree of association. In this research, the grey correlation analysis method is used to study the relationship between energy consumption structure and environmental pollution. The steps of establishing the grey correlation model are as follows:

Set the data reference sequence and the comparison sequence consider the reference sequence, the set of multi-index time domains is $\mathrm{X}_{0}(\mathrm{~A})=\left\{\mathrm{X}_{01}, \mathrm{X}_{02}, \cdots, \mathrm{X}_{0 \mathrm{k}}\right\} \quad(\mathrm{k}=1,2, \cdots, m)$, and $\mathrm{X}_{\mathrm{i}}(\mathrm{A})$ is the set of indicators to be evaluated. Then $\mathrm{X}_{\mathrm{i}}(\mathrm{A})=\left\{\mathrm{X}_{\mathrm{i}}, \mathrm{X}_{\mathrm{i} 2}, \cdots, \mathrm{X}_{\mathrm{ik}}\right\}(\mathrm{i}=1,2, \cdots, n)$. Taking into account the differences in the unit of measure of each factor, it is often necessary to perform a dimensionless treatment of the raw data of each factor. Set $Y_{0}(A)$ as the index sequence of $\mathrm{X}_{0}(\mathrm{~A})$ after dimensionless processing, and $\mathrm{Y}_{\mathrm{i}}(\mathrm{A})$ as the comparison sequence of $\mathrm{X}_{\mathrm{i}}(\mathrm{A})$ after dimensionless processing, then:

$$
\begin{aligned}
& \mathrm{Y}_{0}(\mathrm{~A})=\left\{\mathrm{X}_{01} / \mathrm{X}_{01}, \mathrm{X}_{02} / \mathrm{X}_{01}, \cdots, \mathrm{X}_{0 \mathrm{k}} / \mathrm{X}_{01}\right\}=\left\{\mathrm{Y}_{01}, \mathrm{Y}_{02}, \cdots, \mathrm{Y}_{0 \mathrm{k}}\right\}(\mathrm{k}=1,2, \cdots, m) \\
& \mathrm{Y}_{\mathrm{i}}(\mathrm{A})=\left\{\mathrm{X}_{\mathrm{i} 1} / \mathrm{X}_{\mathrm{i} 1}, \mathrm{X}_{\mathrm{i} 2} / \mathrm{X}_{\mathrm{i} 1}, \cdots, \mathrm{X}_{\mathrm{ik}} / \mathrm{X}_{\mathrm{i} 1}\right\}=\left\{\mathrm{Y}_{\mathrm{i} 1}, \mathrm{Y}_{\mathrm{i} 2}, \cdots, \mathrm{Y}_{\mathrm{ik}}\right\}(\mathrm{i}=1,2, \cdots, n)
\end{aligned}
$$

Based on the grey correlation method, the correlation coefficient $\gamma_{i}$ of the $i^{\text {th }}$ index of $Y_{i}(A)$ and the reference index of $Y_{0}(A)$ in the $k^{\text {th }}$ year after the dimensionless processing is:

$$
\gamma_{\mathrm{i}}(\mathrm{A})=\Delta_{\min } \theta \Delta_{\max } /\left(\Delta_{\mathrm{i}}(\mathrm{A})+\theta \Delta_{\max }\right)
$$

where $\Delta_{\mathrm{i}}(\mathrm{A})$ is the absolute difference of the $\mathrm{i}^{\text {th }}$ index $, \Delta_{\mathrm{i}}(\mathrm{A})=\left|\mathrm{Y}_{\mathrm{i}}(\mathrm{A})-\mathrm{Y}_{0}(\mathrm{~A})\right|, \Delta_{\min }, \Delta_{\max }$ is the minimum and maximum of the absolute difference, for $\theta \in[0,1]$, the general value is 0.5 .

\section{Research Result}

This research focuses on the relationship between energy consumption structure and environmental pollution. In terms of energy consumption, oil consumption (X1), coal consumption (X2), natural gas consumption (X3) and electricity consumption (X4) are selected as comparison sequences. Environmental pollution is based on data availability and accuracy, and selects Beijing industrial $\mathrm{SO}_{2}$ emissions, industrial soot emissions, industrial wastewater discharge and industrial solid waste for quantitative research.

\subsection{Research Data}

This research selects the energy consumption and environmental pollution emissions data of the eight years from 2010 to 2017. The data is adopted from the Beijing Municipal Bureau of Statistics from 2011 to 2018. The oil consumption includes gasoline, kerosene, diesel and fuel oil, which is converted into standard coal for easy calculation. With the 2010 data as a reference sequence, the raw data of energy consumption and environmental pollution are processed in a dimensionless manner. The processed data are shown in Table 1 below. 
Table 3. Dimensionless data on major energy consumption and environmental pollution in Beijing from 2010 to 2017

\begin{tabular}{|c|c|c|c|c|c|c|c|c|}
\hline Year & $\begin{array}{l}\text { Oil } \\
\text { consumption }\end{array}$ & $\begin{array}{l}\text { Coal } \\
\text { consumption }\end{array}$ & $\begin{array}{l}\text { Natural gas } \\
\text { consumption }\end{array}$ & $\begin{array}{l}\text { Electricity } \\
\text { consumption }\end{array}$ & $\begin{array}{l}\text { Industrial } \\
\mathrm{SO}_{2} \\
\text { emission }\end{array}$ & $\begin{array}{l}\text { Industrial } \\
\text { soot } \\
\text { emission }\end{array}$ & $\begin{array}{l}\text { Industrial } \\
\text { wastewater } \\
\text { discharge }\end{array}$ & $\begin{array}{l}\text { Industrial } \\
\text { solid } \\
\text { waste }\end{array}$ \\
\hline 2010 & 1 & 1 & 1 & 1 & 1 & 1 & 1 & 1 \\
\hline 2011 & 1.0703 & 1.0083 & 0.9673 & 1.0059 & 0.9168 & 0.6893 & 0.8944 & 0.8951 \\
\hline 2012 & 1.0545 & 0.8797 & 1.2113 & 0.9634 & 0.8873 & 0.7231 & 0.9520 & 0.8780 \\
\hline 2013 & 1.1000 & 0.8329 & 1.3198 & 0.8223 & 0.7783 & 0.6372 & 0.9838 & 0.8303 \\
\hline 2014 & 1.1304 & 0.7395 & 1.5538 & 0.9787 & 0.6034 & 0.5324 & 0.9504 & 0.8118 \\
\hline 2015 & 1.1681 & 0.4982 & 2.1410 & 0.9578 & 0.3301 & 0.3044 & 0.9301 & 0.5645 \\
\hline 2016 & 1.1651 & 0.3629 & 2.3786 & 1.6056 & 0.1534 & 0.1846 & 0.8821 & 0.5003 \\
\hline 2017 & 1.2253 & 0.2142 & 2.4463 & 1.5952 & 0.0568 & 0.1004 & 0.8799 & 0.5013 \\
\hline
\end{tabular}

\subsection{The Empirical Analysis between Energy Consumption Structure and Environmental Pollution}

The calculation of the correlation coefficient between energy consumption structure and environmental pollution in Beijing first selects the energy consumption and industrial $\mathrm{SO}_{2}$ to calculate the correlation coefficient. Firstly, the difference sequence between the energy consumption sequence and the industrial $\mathrm{SO}_{2}$ sequence is obtained, and the correlation degree between the energy consumption varieties and the industrial $\mathrm{SO}_{2}$ can be got by calculation; in the same way, the correlation degree between various energy consumption varieties and industrial soot, industrial wastewater and industrial solid waste can be got by calculation. The specific data is shown in Table 4 below.

Table 4. Correlation analysis results between major energy consumption and environmental pollution in Beijing from 2010 to 2017

\begin{tabular}{lllll}
\hline & Industrial $\mathrm{SO}_{2}$ & Industrial soot & Industrial wastewater & Industrial solid waste \\
\hline Oil consumption & 0.8253 & 0.7699 & 0.8225 & 0.8452 \\
Coal consumption & 0.9235 & 0.8766 & 0.7751 & 0.9564 \\
Natural gas consumption & 0.6561 & 0.6569 & 0.6250 & 0.6205 \\
Electricity consumption & 0.7350 & 0.8842 & 0.8329 & 0.8401 \\
\hline
\end{tabular}

From the calculation results, the main energy consumption in Beijing, including coal, oil, natural gas and electricity, is highly correlated with environmental pollution, indicating that the main energy consumption has a significant impact on Beijing's environment. The empirical analysis of the grey correlation show that the four environmental pollution factors, which including industrial $\mathrm{SO}_{2}$, industrial soot, industrial wastewater and industrial solid waste were impacted by the consumption of energy products such as oil, coal, natural gas and electricity. The empirical results are as follows:

(1) Industrial $\mathrm{SO}_{2}: \gamma($ coal $)>\gamma($ oil $)>\gamma($ electricity $)>\gamma$ (natural gas). It shows that the coal and oil consumption are highly correlated with the industrial $\mathrm{SO}_{2}$ emission. Among the four energy consumptions, the correlation coefficient between coal consumption and industrial $\mathrm{SO}_{2}$ emissions is $92.35 \%$. The correlation between oil and industrial $\mathrm{SO}_{2}$ emissions is $82.53 \%$. The natural gas consumption has the least impact on industrial $\mathrm{SO}_{2}$ emissions, with a correlation coefficient of $65.61 \%$.

(2) Industrial soot: $\gamma$ (electricity) $>\gamma($ coal $)>\gamma($ oil $)>\gamma$ (natural gas). It shows that the electricity and oil consumption are highly correlated with the industrial soot emission. The correlation coefficient between electricity consumption and industrial soot emission is $88.42 \%$, and the correlation coefficient between oil consumption and industrial soot emission is $81.06 \%$. The impact of natural gas on industrial soot emission is the smallest, with a correlation degree of $65.69 \%$.

(3) Industrial wastewater: $\gamma$ (electricity) $>\gamma$ (oil) $>\gamma$ (coal) $>\gamma$ (natural gas). The correlation coefficient between electricity consumption and industrial wastewater emission is $83.29 \% \%$, indicating the highest impact of oil consumption on industrial wastewater emission. The correlation coefficient among oil and coal and 
industry consumption wastewater discharge are $82.25 \%$ and $77.51 \%$ respectively. The natural gas has the least impact on industrial wastewater, in which the correlation coefficient is $62.50 \%$.

(4) Industrial solid waste: $\gamma($ coal $)>\gamma($ oil $)>\gamma($ electricity $)>\gamma$ (natural gas).The empirical results show that the coal and oil consumption have higher correlation with industrial solid waste, reaching $95.64 \%$ and $84.52 \%$ respectively. The correlation coefficient between electricity consumption and industrial solid waste emissions is $84.01 \%$. The impact of natural gas on industrial solid waste emissions is the smallest, with a correlation coefficient of $62.05 \%$.

\section{Conclusions}

The purpose of this research was to analyze the relationship between energy consumption structure and environment pollution of Beijing. With respect to the research problem, the grey correlation model was developed through organizing the existing theories and findings in studying energy and environment issues of Beijing.

From the grey correlation analysis between energy consumption and environmental pollution in Beijing, the results showed that the oil and coal consumption are highly correlated with environmental pollution. The correlations between coal consumption and industrial $\mathrm{SO}_{2}$, industrial soot and industrial solid waste emissions were all over $80 \%$. In particular, coal consumption had the highest correlation with industrial $\mathrm{SO}_{2}$ and industrial solid waste with correlation coefficient above $92 \%$. The correlation coefficient among oil consumption and industrial $\mathrm{SO}_{2}$, industrial wastewater and industrial solid waste exceed $80 \%$. It was worth noting that electricity consumption was also highly correlated with industrial soot, industrial wastewater and solid waste, and the correlation coefficients were over $82 \%$. The consumption of natural gas has the least impact on the emission of environmental pollution, and the correlation value ranged from $62 \%$ to $66 \%$.

The findings of the study provided an empirical support to how to optimize the energy consumption structure and decrease the environment pollution. The findings of this study also have implications for management practice. Specifically, the result of this research may be useful for management practitioners who are involved in the industrial upgrading and ecological civilization construction in Beijing.

\section{Acknowledgments}

The research is supported by the general project of the national social science foundation of China, "A study on the causes, effects and paths of deepening china-japan-Korea financial cooperation in the context of comprehensive financial liberalization" (No. 19BGJ054).

\section{References}

Beijing Statistical Yearbook (2011). Beijing Municipal Bureau of Statistics (BMBS). Survey Office of the National Bureau of Statistics in Beijing. Beijing Statistical Yearbook. Beijing: China Statistics Press.

Beijing Statistical Yearbook. (2018). Beijing Municipal Bureau of Statistics (BMBS). Survey Office of the National Bureau of Statistics in Beijing. Beijing Statistical Yearbook. Beijing: China Statistics Press.

China Statistical Yearbook. (2018). National Bureau of Statistics of China (NBS). China Statistical Yearbook 2018. Beijing: China Statistics Press.

Fu, Y. (2014). Grey correlation analysis of energy consumption, energy structure and economic growth. Journal of Industrial Technological Economics, 5, 153-160. https://doi.org/10.3969/j.issn.1004-910x.2014.05.019

Liu, M. Y. (2019). Decoupling analysis of economics development and energy consumption in Beijing under the new Normal. Energy of China, 41(1), 39-43. https://doi.org/10.3969/j.issn.1003 - 2355.2019.01.008

Qian, J. (2010). Implement scientific development view and promote sustainable development of China population. Resources and Environment, 20(7), 48-54. ttps://doi.org/10.3969/j.issn.1002-2104.2010.07.008

Tan, B. (2017). Challenges and legal suggestions for Beijing environmental pollution prevention and control. Law Science Magazine, 11, 18-24. https://doi.org/10.16092/j.cnki.1001-618x.2013.11.002

Tao, J., Zhang, L. M., Cao, J. J., \& Zhang, R. J. (2017). A review of current knowledge concerning PM 2.5 chemical composition, aerosol optical properties and their relationships across China. Atmospheric Chemistry and Physics, 17, 9485-9518. https://doi.org/10.5194/acp-2017-271

Wang, J. L., Liu, M. Y., \& Yang, B. (2018). Forecast of Beijing's energy consumption peak and research on countermeasures. Journal of Low Carbon Economy, 7(3), 136-145. ttps://doi.org/10.12677/jlce.2018.73015 
Wang, Y. J., Gu, A. L., \& Zhang, A. L. (2011). Recent development of energy supply and demand in China and energy sector prospects through 2030. Energy Policy, 39, 6745-6759. https://doi.org/10.1016/j.enpol.2010.07.002

Yang, Y., Zhu, D. (2007). The relations between energy consumption and environment from economic view. Resources Environment \& Engineering, 21(1), 71-74. https://doi.org/ cnki:sun:hbdk.0.2007-01-018

Zhang, B., Yuan, X., \& Zhang, X. (2011). Environmental pollution, energy consumption and economic growth. Scientific Decision Making, 12, 20-42. https://doi.org/10.3773/j. issn.1006-4885.2012. 11.020

Zhang, F. Y., Xu, J., \& Wang, L. (2016). Air quality, patterns and otolaryngology health effects of air pollutants in Beijing in 2013. Aerosol and Air Quality Research, 16, 1464-1472. https://doi.org/10.4209/aaqr.2015.05.0297

Zhou W. (2016). The effects, problems and countermeasures of Beijing's ecological civilization construction. Journal of Beijing Union University (Humanities and Social Sciences), 3, 18-24. https://doi.org/cnki:sun:bjlb.0.2015-03-003

Zhu, Q., Luo, Z., \& Hua, M. (2015). Grey correlation analysis of energy production, energy consumption and energy structure. Enterprise Economy, 2, 20-23. https://doi.org/10.13529/j.enterprise.economy.2015.02.004

\section{Copyrights}

Copyright for this article is retained by the author(s), with first publication rights granted to the journal.

This is an open-access article distributed under the terms and conditions of the Creative Commons Attribution license (http://creativecommons.org/licenses/by/4.0/). 